\title{
LPS-treatment of bovine endometrial epithelial cells causes differential DNA methylation of genes associated with inflammation and endometrial function
}

Naveed Jhamat ${ }^{1,2,3}$, Adnan Niazi ${ }^{1,2^{*}}$ (D), Yongzhi Guo ${ }^{4}$, Metasu Chanrot ${ }^{4,5}$, Elena Ivanova ${ }^{6}$, Gavin Kelsey ${ }^{6,7}$, Erik Bongcam-Rudloff ${ }^{1,2}$, Göran Andersson ${ }^{1,8+}$ and Patrice Humblot ${ }^{4 \dagger}$

\begin{abstract}
Background: Lipopolysaccharide (LPS) endotoxin stimulates pro-inflammatory pathways and is a key player in the pathological mechanisms involved in the development of endometritis. This study aimed to investigate LPS-induced DNA methylation changes in bovine endometrial epithelial cells (bEECs), which may affect endometrial function. Following in vitro culture, bEECs from three cows were either untreated (0) or exposed to 2 and $8 \mu \mathrm{g} / \mathrm{mL}$ LPS for $24 \mathrm{~h}$.

Results: DNA samples extracted at $0 \mathrm{~h}$ and $24 \mathrm{~h}$ were sequenced using reduced representation bisulfite sequencing (RRBS). When comparing DNA methylation results at $24 \mathrm{~h}$ to time $0 \mathrm{~h}$, a larger proportion of hypomethylated regions were identified in the LPS-treated groups, whereas the trend was opposite in controls. When comparing LPS groups to controls at $24 \mathrm{~h}$, a total of 1291 differentially methylated regions (DMRs) were identified (55\% hypomethylated and 45\% hypermethylated). Integration of DNA methylation data obtained here with our previously published gene expression data obtained from the same samples showed a negative correlation ( $r=-0.41$ for gene promoter, $r=-0.22$ for gene body regions, $p<0.05$ ). Differential methylation analysis revealed that effects of LPS treatment were associated with methylation changes for genes involved in regulation of immune and inflammatory responses, cell adhesion, and external stimuli. Gene ontology and pathway analyses showed that most of the differentially methylated genes (DMGs) were associated with cell proliferation and apoptotic processes; and pathways such as calcium-, oxytocin- and MAPKsignaling pathways with recognized roles in innate immunity. Several DMGs were related to systemic inflammation and tissue re-modelling including HDAC4, IRAK1, AKT1, MAP3K6, WnT7A and ADAMTS17.

Conclusions: The present results show that LPS altered the DNA methylation patterns of bovine endometrial epithelial cells. This information, combined with our previously reported changes in gene expression related to endometrial function, confirm that LPS activates pro-inflammatory mechanisms leading to perturbed immune balance and cell adhesion processes in the endometrium.
\end{abstract}

Keywords: LPS, Bovine endometrial epithelial cells, RRBS, Endometritis, Inflammation, Implantation

\footnotetext{
*Correspondence: adnan.niazi@slu.se

${ }^{\dagger}$ Göran Andersson and Patrice Humblot shared senior authors.

'Department of Animal Breeding and Genetics, Section of Molecular Genetics,

Swedish University of Agricultural Sciences, Uppsala 750 07, Sweden

${ }^{2}$ SLU-Global Bioinformatics Centre, Swedish University of Agricultural

Sciences, Uppsala 750 07, Sweden

Full list of author information is available at the end of the article
}

(c) The Author(s). 2020 Open Access This article is licensed under a Creative Commons Attribution 4.0 International License, which permits use, sharing, adaptation, distribution and reproduction in any medium or format, as long as you give appropriate credit to the original author(s) and the source, provide a link to the Creative Commons licence, and indicate if changes were made. The images or other third party material in this article are included in the article's Creative Commons licence, unless indicated otherwise in a credit line to the material. If material is not included in the article's Creative Commons licence and your intended use is not permitted by statutory regulation or exceeds the permitted use, you will need to obtain permission directly from the copyright holder. To view a copy of this licence, visit http://creativecommons.org/licenses/by/4.0/ The Creative Commons Public Domain Dedication waiver (http://creativecommons.org/publicdomain/zero/1.0/) applies to the data made available in this article, unless otherwise stated in a credit line to the data. 


\section{Background}

Endometritis is a common disease in post-partum dairy cows with negative impacts on reproductive performance and increased risk of culling, thus, causing major economic losses to the dairy industry $[1,2]$. In case of infection by Gram negative bacteria such as E. coli, these effects are mediated by the lipopolysaccharide (LPS) endotoxin. LPS has been reported to impair reproductive performance in cattle [3] and affect early pregnancy in ewes [4]. The Toll-like receptor (TLR) signaling pathway is a central component of the primary innate immune response to pathogenic challenge. LPS stimulates the host's innate immune response by increasing TLR4 and MyD88-dependent signaling $[5,6]$ and subsequently activates the expression of pro-inflammatory cytokines and chemokines, such as interleukin 1A (IL-1A), IL-6 and IL-8 [5-8] and activation of JAK / STAT signaling pathway [7]. These pathways are pivotal for host defense against pathogens during endometritis [7].

Appropriate balance in production of cytokines and growth factors in endometrial cells is important for embryo development and successful implantation. During endometritis, these processes may indirectly be compromised due to elevated levels of cytokines, affecting endometrial receptivity and subsequently perturbing critical embryo-maternal interactions $[9,10]$.

Epigenetic modifications, such as DNA methylation, have been shown to be associated with changes in gene expression in the endometrium during early pregnancy [11], and may regulate the uterine response to embryo implantation $[12,13]$. Several studies on gene expression and DNA methylation mainly performed in the human species have highlighted important genes and pathways affecting reproductive function during early or late pregnancy stages [14-19]. Other studies addressed the impact of infection and LPS on the DNA methylation status of immune cells. In human macrophages, LPS induced specific methylation changes lead to inactivation of pro-inflammatory pathways [20].

Endometrial epithelial cells (EECs) are key players in the defense of the uterus against most inflammatory diseases by triggering immune responses [21-23]. During endometritis and at early stages of pregnancy, gene expression changes related to pathways including cell adhesion, cytoskeleton remodeling and cell proliferation were reported [24-26]. Despite this, in the cow, the information related to epigenetic regulation of the above pathways and of the immune response in EECs in case of uterine infection is scarce, to the best of our knowledge. DNA demethylation in bovine endometrial cells was observed after $24 \mathrm{~h}$ of LPS exposure in specific sites of IL-6 and IL- 8 promoter regions [27]. However, genome-wide epigenetic approaches have not been used so far to investigate changes in DNA methylation of the bovine endometrial epithelial cells (bEECs) in response to molecules from pathogens and there is a lack of information on the epigenetic mechanisms induced by infection, which may contribute to alterations of endometrial function.

The aim of the present study was to identify genomic regions presenting differential DNA methylation in bEECs following exposure to LPS, by using reduced representation bisulfite sequencing (RRBS). We also investigated here how DNA methylation changes are correlated with the transcriptomic response to LPS from RNAseq data obtained from the same cell samples and treatment conditions [28]. Thus, providing insights in alterations of DNA methylation induced by LPS possibly influencing endometrial function.

\section{Results}

\section{RRBS and DNA methylation profile}

DNA methylation profiles were established from a set of 12 samples of post primary bEECs; three untreated samples at time $0 \mathrm{~h}$ and nine samples at $24 \mathrm{~h}$ after exposure to LPS $(0,2,8 \mu \mathrm{g} / \mathrm{mL}$; Additional file 1: Figure S1). These concentrations of LPS may mimic those previously reported in cow uterine fluid following cases of clinical endometritis and/or in vivo experimental infection $[29,30]$. They were chosen here also, due to different phenotypic responses to LPS in terms of cell survival and proliferation profiles and proteomic profiles [31, 32]. For the sake of consistency when studying correlation between DNA methylation and gene expression results, the same biological material was used (same cells exposed to same LPS dosages and time point) as in our former RNAseq study [28]. Overall, RRBS yielded a total of 17-21 million reads per sample. After quality filtering, $60-62 \%$ of the reads were successfully aligned to the bovine reference genome sequence (bosTau8), whereas $40-50 \%$ of the reads were uniquely mapped. In total, we identified 2.1-2.3 million CpG sites per sample, of which 1.93 million were covered in all samples, representing $7.1 \%$ of the total number of CpGs $(\sim 27 \mathrm{M})$ in the Bos taurus genome. Raw sequencing data and mapping statistics are summarized in Additional file 2: Table S1.

From the RRBS data, differentially methylated regions (DMRs) throughout the bovine genome in response to LPS treatment were identified. CpG site coverage distribution showed that a large number of $\mathrm{CpG}$ sites had coverage of 10 reads or below in all samples (Additional file 1: Figure S2). A total of 700,323 CpG regions with at least one CpG site and read coverage $\geq 5$ in all samples were obtained after tiling the genome for $100 \mathrm{bp}$ regions. From those, 157,202 regions that contained $\geq 2$ CpG sites were used for differential methylation analysis. Principal component analysis separated the samples according to individuals and did not reveal a strong effect of LPS on 
the DNA methylation pattern. This was related to the high degree of correlation between methylation profiles of treated and untreated groups (Fig. 1a; Additional file 1: Figure S3). However, differential DNA methylation analyses detected 511 and 469 significant DMRs ( $q$-value $<0.05)$ in LPS- $2 \mu \mathrm{g}$ and LPS- $8 \mu \mathrm{g}$, respectively, when compared to $24 \mathrm{~h}$ untreated control samples. The comparison between $0 \mathrm{~h}$ and $24 \mathrm{~h}$ control groups detected 822 DMRs of which 30\% were hypomethylated and 70\% were hypermethylated (Additional file 2: Table S2). We noted that a relatively low number of DMRs were shared between the $2 \mu \mathrm{g}$ and $8 \mu \mathrm{g}$ LPS groups when compared to $24 \mathrm{~h}$ control (Fig. 1b). In an attempt to recover DMRs that might be discarded due to coverage threshold, we combined data from the 2 and $8 \mu \mathrm{g}$ LPS samples and compared them to $24 \mathrm{~h}$ control samples. The combinedLPS analysis detected 803 DMRs, sharing many DMRs identified in the two LPS groups (Fig. 1b). Finally, to avoid omission of functionally important methylated regions, we included in the analysis, those DMRs that did not withstand the $q$-value threshold in combined-LPS comparison but were significantly differentially methylated in either $2 \mu \mathrm{g}$ or $8 \mu \mathrm{g}$ LPS-treated samples. A total of 1291 DMRs were then identified and used for further analysis. From those, 707 (55\%) were hypomethylated and 584 (45\%) hypermethylated (Additional file 2: Table S3). The effect of LPS on the bEECs methylome showed similar methylation patterns in all treated groups (Fig. 1c). LPS treatment induced a higher proportion of hypomethylation when compared to control DMRs identified in the comparison between time $24 \mathrm{~h}$ and $0 \mathrm{~h}$ in controls (Fig. 1d).

\section{Genomic distribution of DMRs}

The chromosomal distribution of the DMRs was determined to assess whether or not DMRs were associated to specific chromosomal features. The distribution of DMRs was skewed towards chromosomal ends (Fig. 2a). The distribution of total targeted regions $(n=157,202)$ was not associated with telomeric regions $(20 \mathrm{~kb})$ of the chromosomes. On the contrary, sub-telomeric regions (within $2 \mathrm{Mb}$ to telomeres) were significantly enriched for DMRs compared to non-telomeric regions (Fisher's Exact, $p<1.14 \mathrm{e}-05)$. In addition, associations of DMRs with the number of genes per chromosome and size of chromosomes were tested (Fig. 2b). A significant positive correlation was found between the number of DMRs and the number of genes per chromosome $(r=0.45, p=$ 0.011). However, no significant correlation was noted with chromosomal size $(r=0.32, p=0.084)$. Interestingly, 143 DMRs were detected on the $\mathrm{X}$ chromosome, which is twice as many compared to the average number of DMRs located on the autosomal chromosomes. This effect on gross differences in DMRs on the X chromosome compared with other chromosomes was independent of CpG richness of all chromosomes and targeted

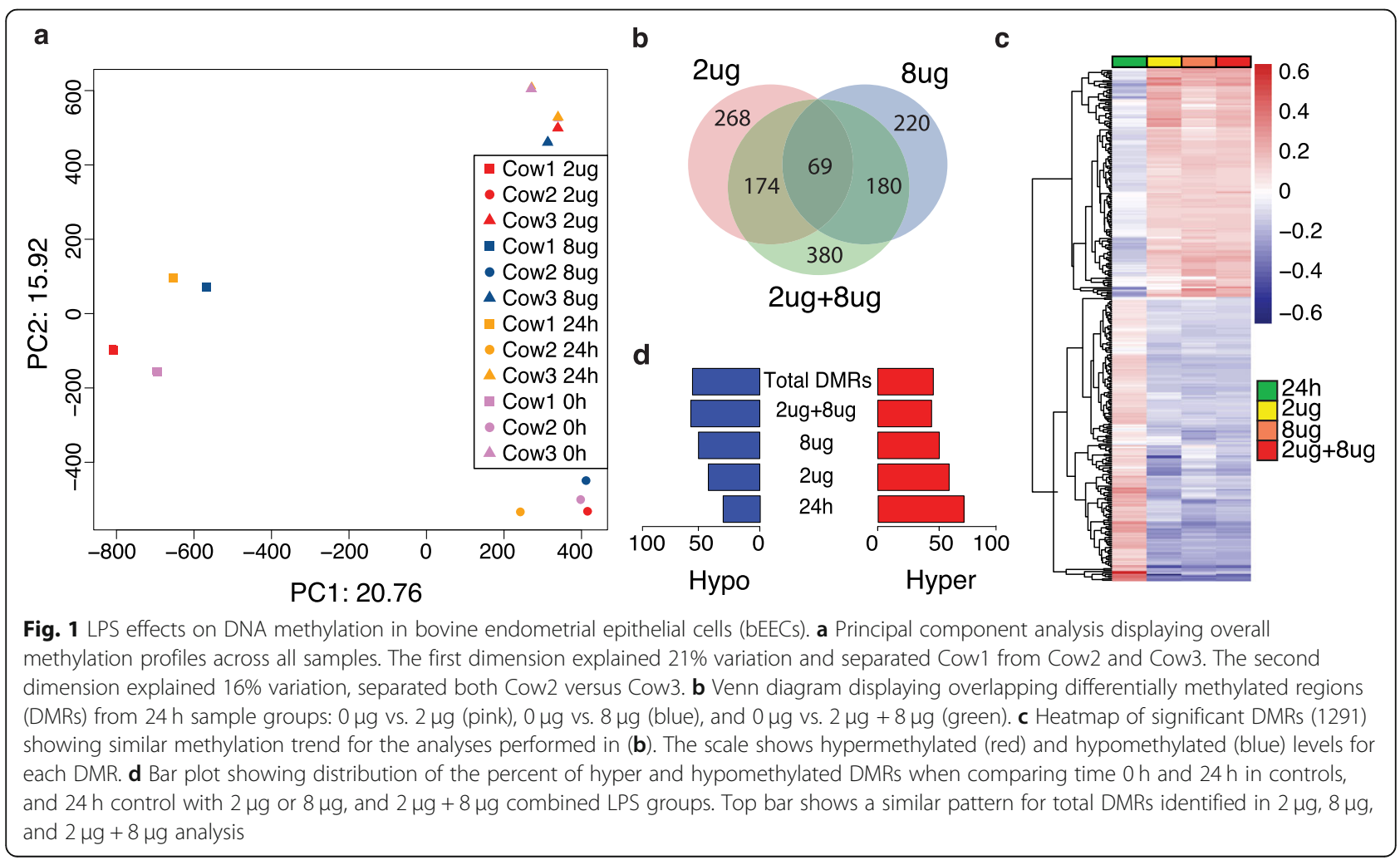


a

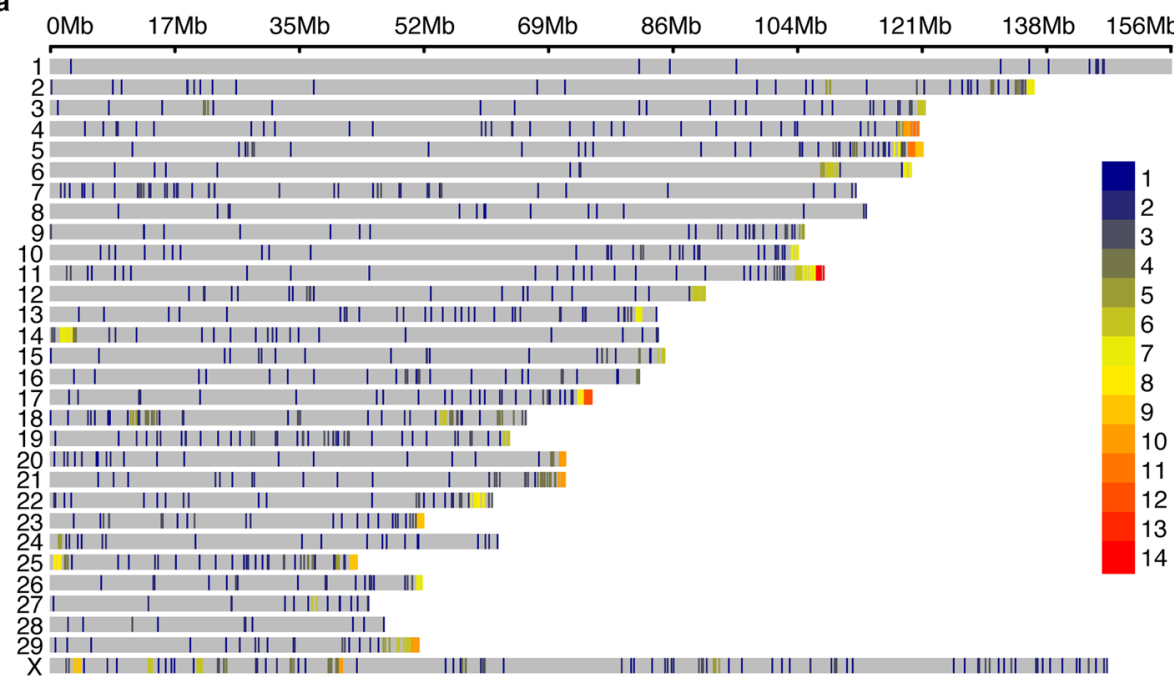

b
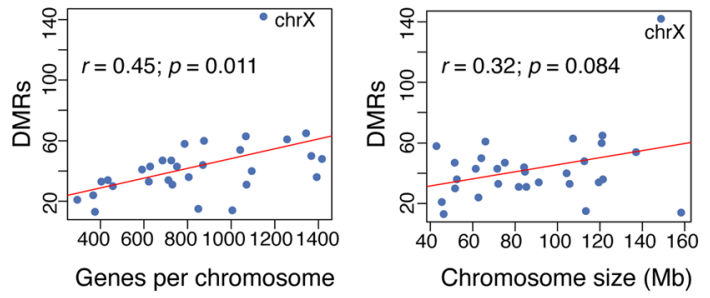

c

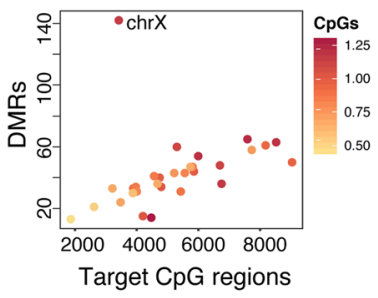

d
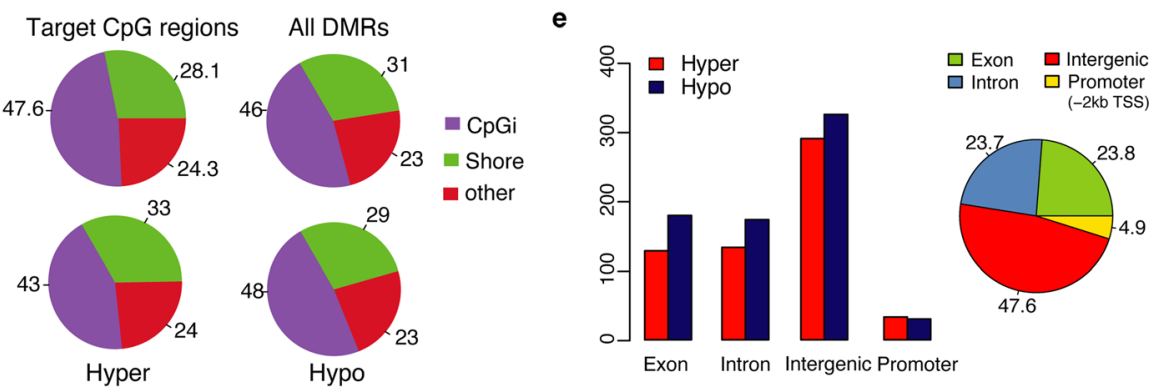

Fig. 2 Genomic distribution of differentially methylated regions (DMRs). a Distribution of significant DMRs on 30 chromosomes of Bos taurus. Horizontal axis displays the chromosome length; 1-14 legend insert indicates the DMR density within 1 Mbp window size. b Scatterplots showing correlation of DMRs with number of genes per chromosome (left) and size of chromosomes (right). The Pearson's correlation coefficients are shown on each plot. c Scatterplot showing distribution of DMRs against all targeted CpG regions (100 bp) on each chromosome. Colour intensity shows CG dinucleotide occurrence (million as unit) in the chromosomes. $\mathbf{d}$ Pie chart shows percentages of DMRs location in CpG islands, shores and other genomic regions. e Bar plot and pie chart shows distribution of DMRs in genic and non-genic regions. Exons and introns have annotation precedence over promoter regions, which are downstream ( $2 \mathrm{~kb}$ ) of transcription-start sites (TSSs). For promoters, only DMRs $2 \mathrm{~kb}$ upstream of TSSs are shown

regions (Fig. 2c). When analyzing the distribution of DMRs in relation to genes and CpG islands $46 \%$ of the total number of identified DMRs were located in CpG islands, $31 \%$ at the shores, while $23 \%$ were located in other genomic regions (Fig. 2d), which corresponds to enrichment of these regions when using RRBS. A similar proportion of DMRs was located in intergenic regions $(47.6 \% ; n=615)$ and within genes $(47.5 \% ; n=613)$, whereas $4.8 \%(n=63)$ were located in promoter regions ( $2 \mathrm{~kb} 5^{\prime}$ of the transcription start site) (Fig. 2e). The 600 differentially methylated genes (DMGs) having one or more DMRs included 589 protein-coding genes, seven miRNA, and four pseudogenes (Additional file 2: Table S4). Among genes that contained at least three DMRs in the gene body and promoter regions, NSG1 had the highest number with five DMRs; four DMRs were found in FAM19A5, SARDH and ENSBTAG00000046364, while genes containing three DMRs were PTMA, SLC2OA2, IRAK1, PCDHGC3, HDAC4, VIPR2, C9orf172 (AJM1), and ENSBTAG00000008542. 


\section{Correlation between DNA methylation and gene expression}

The potential effect of DNA methylation on gene expression was characterized by comparing methylation and RNA expression data previously obtained by RNAseq on the same cell samples [28]. The transcriptomewide association between gene expression and DNA methylation within promoter regions and gene bodies was examined. There was a significant negative association between mean methylation of promoter regions and gene expression (Spearman rho $=-0.41 ; p<2.2 \mathrm{e}-16$; Fig. 3a). Although weaker, a significant negative relationship was also observed between gene body methylation and gene expression (Spearman rho $=-0.22, p<2.2 \mathrm{e}-16$; Fig. 3b).

In a further step, 80 genes for which there could be a functionally important effect of LPS on both DNA methylation and gene expression $(\mid \Delta$ methylation $\mid>5 \%$ and $\mid \Delta$ expression $\log _{2} \mathrm{FC} \mid>1$ ) were identified. For both promoters and gene body regions, there was no evidence for unequal distribution of genes $\left(x^{2}=3.4, p=0.33\right.$ and $\mathrm{X} 2=1.47, p=0.68$, respectively). However, 39 genes (49.9\%) showed an inverse relationship between their degree of DNA methylation (in promoter or body) and gene expression (Fig. 3c, d; Additional file 2: Table S5). A combined functional analysis focusing only on the genes showing an inverse relationship (above threshold) revealed that these were related to ion/calcium ion transport and signal transduction processes.

\section{Gene ontology and pathway analyses}

In order to further characterize genes associated with DMRs, gene ontology and pathway analysis were carried out using an online platform DAVID [33, 34]. When a

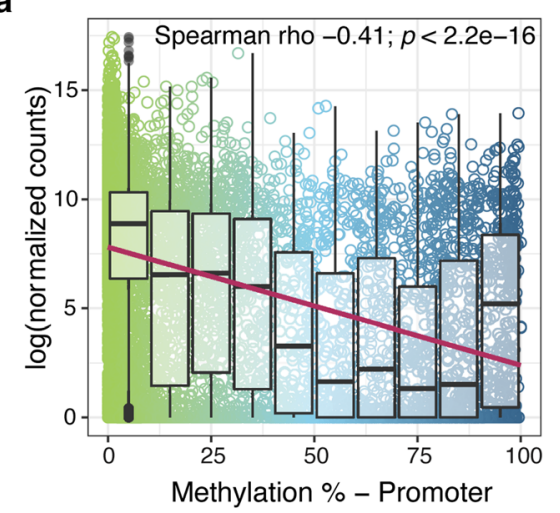

C

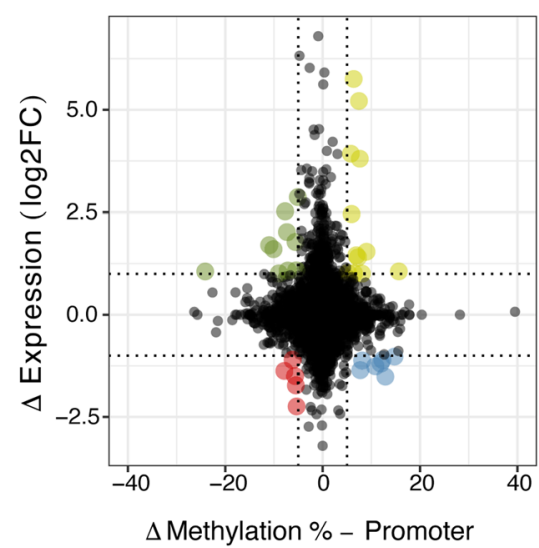

b

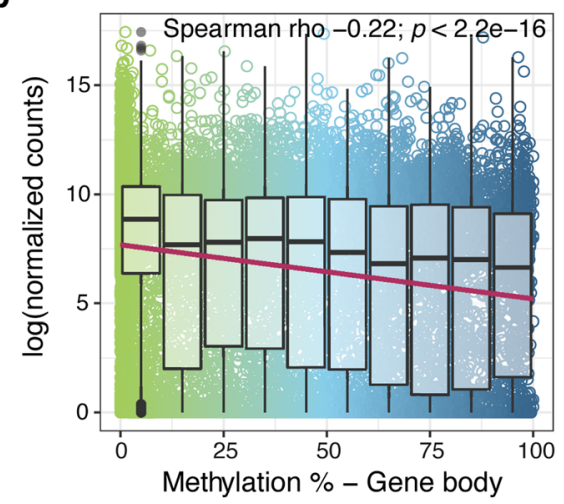

d

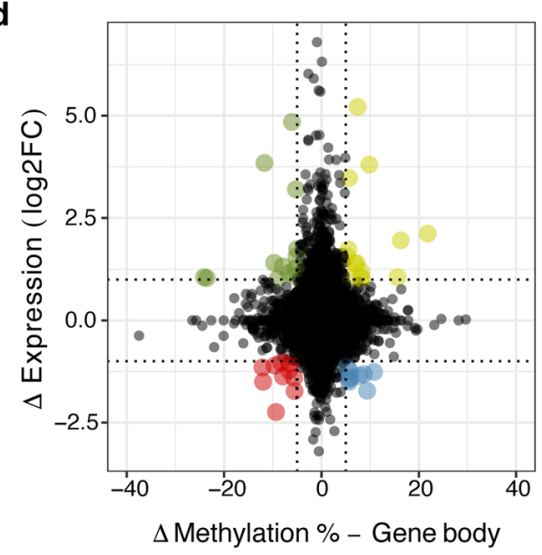

Fig. 3 Integration of gene expression and methylome data. a Scatterplot showing mean gene expression and boxplot showing mean DNA methylation in differentially methylated regions (DMRs) in treated group for DMRs in promoters (a) and DMRs in gene bodies (b), with lines representing a linear trend. Bars in the box plot correspond to the median. The lower and upper hinges correspond to the first and third quartiles (the 25th and 75th percentiles). The lower/upper whisker extends from the hinge to the smallest/largest value no further than $1.5 * I Q R$ (inter quartile range) from the hinges. c-d Scatterplots displaying the effect of lipopolysaccharide (LPS) on the transcriptome and the methylome when compared to the control group; change in gene expression ( $\log _{2}$ Fold Change) is plotted against change in DNA methylation for $\mathbf{c}$ promoters of 12,115 genes and (d) gene bodies of 13,263 genes. Highlighted points denote genes with $\mid \Delta$ Methylation $\mid>5 \%$ and $\mid \Delta$ expression $\log _{2} \mathrm{FC} \mid>1$; hypermethylated/increased expression (yellow), hypermethylated/lower expression (blue), hypomethylated/increased expression (green) and hypomethylated/lower expression (red) 
using the 600 genes having one or more DMRs (Additional file 2: Table S4), GO analysis revealed significant overrepresentation of biological and molecular functions related mainly to signal transduction, cell proliferation, apoptotic process, vasculogenesis and embryo development (Fig. 4a, Additional file 2: Table S6). Among the molecular functions, DMRs were enriched in genes encoding proteins involved in calcium and zinc ion binding, voltage-gated calcium channel activity, ATP binding and transcription coactivator activity (Additional file 2: Table S7). Significant enrichment of several pathways was found using the KEGG database: notably, calcium-, MAPK-, vascular smooth muscle contraction-, Oxytocin- and cGMP-PKG signaling pathways (Fig. 4b). In addition, WikiPathways analysis revealed a network of genes known to be involved in multiple functions (Additional file 1: Figure S4, Additional file 2: Table S8). Notably among genes differentially methylated with one or multiple DMRs, several encode proteins involved in immune function and inflammatory processes (HDAC4, $A K T 1$, and IRAK1), proliferation and apoptosis (WNT/ $\beta$-catenin signaling WNT7A, MAP3K6, BCL2), tissue remodeling (ADAMTS2, ADAMTS14, ADAMTS17) and the corticotropin releasing hormone signaling pathway, which relates to both trophoblast invasion (TFAP2A, hypomethylated DMR in exon 2) and angiogenesis (PRKCA and PRKCG, hypomethylated in intron 13 and hypermethylated in exon 5 , respectively).
Pro-inflammatory mechanisms may be favored by epigenetic changes in the HDAC4 gene (two hypomethylated DMRs in intron 1 and one hypermethylated DMR in intron 2) and hypermethylation of two DMRs associated to $A K T 1$ gene (in $A K T 1$ intron 1). In addition, the hypomethylation of IRAK1 promoter and two hypomethylated DMRs on exon 1 and CpG island, may contribute to reinforce pro-inflammatory reactions through activation of TLR signaling. The Wnt7A gene, which is involved in proliferation, contains two hypomethylated DMRs in intron 3 and is over-expressed as shown from RNAseq data. We observed also the hypomethylation of one DMR in each of the promoters of MAP3K6 and BCL2 genes that regulates apoptosis. The methylation changes in HDAC4 as reported above may affect also tissue remodeling as low expression has been associated with increased MMPs activity. This is consistent with the hypomethylation and increased expression of ADAMTS17.

\section{Discussion}

Studies in both the human and bovine species have shown that the endometrial DNA methylome is highly dynamic and is submitted to changes throughout the oestrus cycle [35, 36], at time of early pregnancy [12] and relating to reproductive diseases [36, 37]. Several studies aimed at deciphering epigenetic changes in various types of cells following LPS challenge [27, 38, 39]. However, to our knowledge, this is the first attempt made to study genome-wide DNA methylation changes in a pure

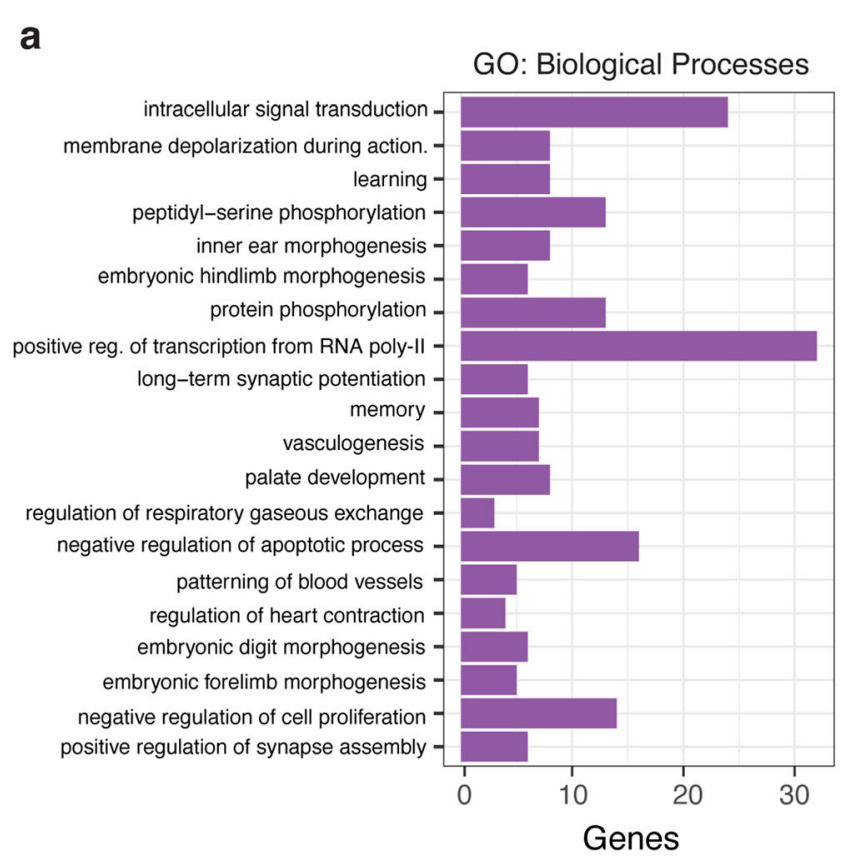

b

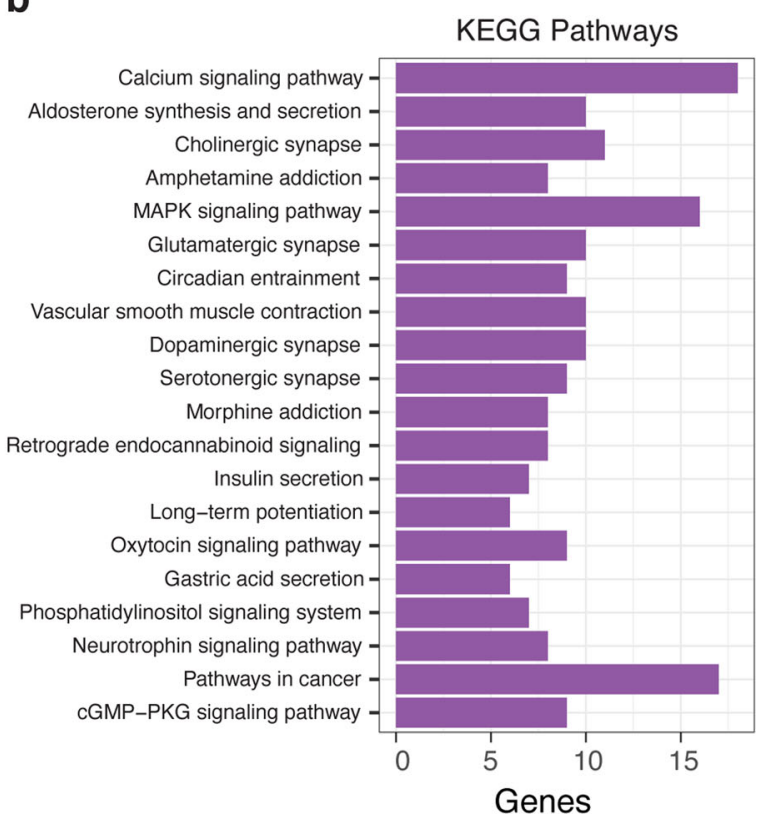

Fig. 4 Gene Ontology (GO) and pathway analyses of genes located in the vicinity of significant differentially methylated regions (DMRs). Bar plots displaying enriched (a) biological processes GO terms and (b) KEGG pathways for DMR annotated genes. The plots show significantly enriched GO terms and pathways $(p<0.05)$ 
population of bovine endometrial epithelial cells (bEECs) exposed to LPS. Differentially methylated regions (DMRs) were identified here after controlling for the individual cow effects in the analysis and using combined results for 2 and $8 \mu \mathrm{g} / \mathrm{ml}$ LPS. In addition, for subsequent interpretation, only significant DMRs were kept which were found consistent between the $2 \mu \mathrm{g}$ and $8 \mu \mathrm{g} / \mathrm{ml}$ dosages and in all three cows. The remaining significant DMRs were further scrutinized for changes reported in the literature especially for those relating to differential gene expression shown in our RNAseq study from the same cells [28].

In our dataset, LPS-treated groups expressed a significant trend for global DNA hypomethylation whereas, during the same period of time, the inverse trend was observed in controls. Despite differences in the LPS dosage and time of observation used, our results are consistent with previous studies in human and mouse showing that bacterial and viral infection induces hypomethylation of host cell DNA [40-42] and the decrease in methylation observed in other bovine cell types following LPS challenge [27, 38]. Globally, DNA methylation changes were enriched in sub-telomeric regions. This is in accordance with the fact that regions adjacent to telomere are rich in CpG islands [43, 44]. Although methylation changes induced by LPS occurred on all chromosomes they were more abundant on the $\mathrm{X}$ chromosome. Interestingly, the $\mathrm{X}$ chromosome had more hypomethylated genes compared with the autosomal chromosomes. Enrichment of DMRs and aberrant DNA hypomethylation of the $\mathrm{X}$ chromosome genes have also been reported in uterine leiomyoma [45] and in ovarian, cervical and breast cancers $[46,47]$.

The analysis of individual DMRs revealed that a number of them mapped to genes involved in the control of endometrial function and/or were related to endometrial dysfunction and infertility as documented mainly in humans and mice. The three main pathways associated specifically with the control of endometrial function, namely $i$ ) proliferation and differentiation, $i$ ) cell migration, cell adhesion and extracellular matrix remodeling and iii) immune responses will be subsequently discussed especially in the light of corresponding changes in gene [28], protein expression [32], and phenotypic response to LPS [31] from the same cells.

\section{Cell proliferation and differentiation}

Class II histone deacetylases (HDACs) are signal transducers often acting as co-repressors of transcription by removing histone acetylation [48], thereby influencing chromatin structure. The over-expression of HDACs such as HDAC4 has been associated to pathologies including cancer [49, 50]. HDACs can promote cell proliferation through repression of cyclin dependent kinase inhibitors such as p21 and simultaneous activation of CDK1 and CDK2 [51, 52]. The impacts of LPS on HDAC4 methylation associated with a lower expression of several members of the HDAC's family [28] on the proliferation of bovine endometrial cells would need specific investigations.

Wnt signaling pathway is also involved in cell proliferation and differentiation in the endometrium. Among genes from this family, Wnt7A encodes a key protein for the control of $\beta$-catenin and its increased expression is observed during the proliferative phase in human endometrial luminal epithelial cells [53]. Increased expression of these genes has been associated to proliferative activity of cancer cells [54] and resulted in endometrial dysfunction with altered uterine receptivity for embryo implantation $[55,56]$ which may result from deregulation of downstream genes important for endometrial function such as FOXa2, $L I F$, and MSX1 [57].

Overall, epigenetic alterations corresponding to HDACs and WNT signaling are consistent with associated changes in gene expression induced by LPS. Further studies would be needed to demonstrate their specific role as part of the mechanisms explaining the strong proliferative phenotype observed in this model [31] and in different cell types [58].

\section{Cell migration, cell adhesion and extracellular matrix remodeling}

Various effects of LPS on certain proteins from the ADAM's family are the metalloproteases, which control fibrillary collagen processing and extracellular matrix organization. From our recent RNAseq results, the over-expression of ADAMTS1 and ADAMTS17 mRNAs were observed. Some of the roles ADAMTS1 on endometrial function have been described whereas less information exists for ADAMTS17. ADAMTS1 participates in the bovine endometrial remodeling at time of implantation and placental development [59], promotes epithelial cell invasion [60], and favors migration and alter adhesion [61, 62]. However, DNA methylation changes found here concerned ADAMTS2, ADAMTS14 and ADAMTS17. The over-expression of ADAMTS17, has been associated to increased cell growth in cancer cells [63], and its hypo-methylation and over-expression from RNAseq [28] are consistent with the proliferative phenotype we observed and increased expression of proteins involved in tissue remodeling, and alterations of cell structure and cell adhesion pathways found in the same cells [32].

DNA methylation changes in genes from the corticotropin signaling network could be of biological significance due to the possible involvement of the proteins encoded by these genes in trophoblast invasion (TFAP2A) [63-65] and vascularization (PRKCA and PRKCG) [6668]. Although interesting in view of future comparative studies, their role for tissue remodeling could be less 
critical in this model, as none of these genes were differentially expressed in response to LPS treatment [28].

\section{Inflammation and immune responses}

Multiple signaling pathways are indeed activated following interaction between LPS and its most important receptor TLR4. This pleiotropic signaling response after activation of Toll-like receptors is likely critical to ensure efficient innate immune defenses against pathogenic bacteria. The underlying molecular mechanisms behind such sustained functional effects leads to changes in DNA methylation at regulatory regions of genes encoding proteins involved in such pathways. This change in chromatin structure in transcriptional regulatory regions results in the consequential changes of mRNA expression. Thus, LPS-TLR4 interactions leads to massive reprogramming of innate immune-mediated response pathways and our results reveal such changes at both the transcriptional and epigenetic levels measured at 24 h. Several studies have shown that class II HDACs such as HDAC4 are also key regulators of inflammatory response in immune cells with either pro- or antiinflammatory roles [69-71]. Due to these roles, the functional significance of multiple differential methylation of this gene would deserve further studies.

AKT1 regulates negatively the immune response and specifically the production of IFN $\beta$ through the inhibition of both TLR-induced MyD88 phosphorylation and NF-kB/ IRF3 signaling [72]. In contrast, Interleukin-1 receptorassociated kinases (IRAKs) are key proteins regulating positively both IL-1R- and TLR-mediated signaling [73]. As mentioned above, further work is needed to identify the specific steps and mechanisms involved in differential methylation observed here. However, it may be hypothesized from these results that in LPS-treated cells, the strong activation of the TLR-NF- $k \beta$ pathway, and the over expression of TNF receptor associated factors (TRAFs) acting as NF-k $\beta$ activators [28] may result from the hypermethylation of $A K T 1$, which normally represses the above pathway and the hypomethylation of IRAK1, which activates TLR signaling.

We observed also a differential methylation of the peroxisome proliferator activated receptor alpha (PPARA, hypomethylation in intron 1), which could be of interest due to its possible role in enhancement of inflammation and restoration of physiological conditions in the endometrium following LPS challenge [74].

Despite a short time of exposure and the relatively low LPS dosage used in this study when compared to concentrations observed during natural or experimental infection [26, 29] a significant number of epigenetic changes which were related to genes involved in endometrial function were observed. It is possible that the epigenetic changes induced by LPS observed here could contribute to long term disturbances of gene expression and endometrial function which may not be favorable to tissue recovery and the establishment of pregnancy. Future studies, based especially on systems allowing long term cell culture and combining the different types of endometrial cells, would deserve further investigations to fully demonstrate the biological significance of these methylation changes in the context of disease.

\section{Conclusions}

LPS induces changes in DNA methylation patterns of bovine endometrial epithelial cells, towards mainly hypomethylation that correlates with overall increased gene expression. LPS affects some specific genes and networks related to inflammation, cell proliferation, cell migration and tissue repair and vascularization. The possible impacts of these changes in methylation marks on long term alterations of endometrial receptivity and implantation would deserve further investigation.

\section{Methods \\ Isolation of bovine endometrial epithelial cells}

The uterine horns from three Swedish Red Breed cows were collected from slaughterhouse (Lövsta, Uppsala, Sweden) and were immediately transferred to the laboratory on ice. Cell isolation was performed within $1 \mathrm{~h}$ after slaughter as described previously [28]. Briefly, small pieces $(2-3 \mathrm{~mm})$ of bovine endometrial tissue were incubated for $2 \mathrm{~h}$ at $39^{\circ} \mathrm{C}$ with $250 \mathrm{U} / \mathrm{mL}$ of collagenase IV (Sigma, St. Louis, MO, USA) and $250 \mathrm{U} / \mathrm{mL}$ of hyaluronidase (Sigma), in PBS containing $2 \%$ bovine serum albumin (BSA). The bEECs were separated from fibroblasts and blood cells by using a $40 \mu \mathrm{m}$ cell strainer. Then bEECs were cultured at $39^{\circ} \mathrm{C}, 5 \% \mathrm{CO}_{2}$ with $\mathrm{F}-12$ medium with $10 \%$ of fetal bovine serum (FBS, Gibco ${ }^{\text {tw }}$ heat inactivated, virus and mycoplasma free, South America Origin). Sub-cultivations were performed when epithelial cells attained approximately $90 \%$ confluence. The purity of the epithelial cell culture was estimated by morphological observation and confirmed by anticytokeratin 18 antibody (Abcam, Cambridge, UK) and anti-vimentin V9 antibody (Abcam) immunofluorescence staining. Flow cytometer analysis further demonstrated a high degree of purity $>98 \%[31,75]$. Falcon ${ }^{\circ}$ $25 \mathrm{~cm}^{2}$ rectangular canted neck cell culture flask with vented cap were used for cell culture (Falcon, ref. 353, 108). According to the manufacturer, the nonpyrogenic test was less than $0.1 \mathrm{EU} / \mathrm{mL}$.

\section{LPS challenge and genomic DNA isolation}

According to the guide from Sigma, LPS (L2630-10MG O111:B4, Sigma-Aldrich) was reconstituted by $2 \mathrm{~mL}$ LAL reagent water (W50-640, Lonza, Walkersville, MD, 
USA) to a stock concentration of $5 \mathrm{mg} / \mathrm{mL}$. In addition, according to the certificate of analysis from Sigma, the potency (Sample Endotoxin Unit, EU/mg) was $\geq 500,000$ EU/mg. The reconstituted LPS was tested with PyroGene recombinant Factor $\mathrm{C}$ endotoxin detection system (Catalog No.: 50-658 U, Lonza) in our lab, which showed $\geq 600,000 \mathrm{EU} / \mathrm{mg}$. At passage 5, in vitro cultured bEECs were either unexposed (control) or exposed to 2 or $8 \mu \mathrm{g} /$ mL E. coli LPS (O111:B4; Sigma). These concentrations of LPS, which may mimic those during days after acute infection, are in the lower range of those previously reported in cow uterine fluid in case of clinical endometritis and/or in vivo experimental infection [29, 30]. They were also chosen here, based on our previous experiments showing effects of LPS on cell survival and proliferation profiles and proteomic profiles [31,32] and the same biological material was used (same cells exposed to same LPS dosages and time point) as in our former RNAseq study [28]. The bEECs were collected at time 0 $\mathrm{h}$ (before LPS challenge) and $24 \mathrm{~h}$ after challenge as in $[27,28]$, by using TrypLE ${ }^{\mathrm{Tu}}$ express (Gibco-BRL 12605) and washed twice with Dulbecco's PBS (DPBS; Life Technologies Inc. Gibco-BRL, Grand Island, NY, USA). Approximately two million cells were obtained from each treatment and kept at $-80^{\circ} \mathrm{C}$. Genomic DNA was extracted by using the Allprep DNA/RNA/miRNA Universal Kit (Qiagen, Hilden, Germany). Each prepared DNA sample was tested by nanodrop to determine the purity, quality and quantity. For all samples, the ratios of the absorbance at $260 \mathrm{~nm}$ and $280 \mathrm{~nm}(\mathrm{~A} 260 / 280)$ and at $260 \mathrm{~nm}$ and $230 \mathrm{~nm}(\mathrm{~A} 260 / 230)$ were between $1.8-2.0$ and $2.1-2.4$, respectively.

\section{Library preparation and sequencing}

Libraries for RRBS were generated by $M s p$ I digestion of the DNA followed by end-repair/A-tailing and $5 \mathrm{mC}$ adaptor ligation; bisulfite conversion; and subsequent PCRs. Libraries were sequenced at The Babraham Institute, UK using Illumina HiSeq 2500 which generated 17-21 million 50 bp single-end reads per sample.

\section{Read mapping and identification of DMRs}

Raw reads were trimmed for low quality sequences, and adapter sequences were removed using Trim Galore [76]. Filtered reads were then aligned to the bovine reference genome sequence (bosTau8 UMD3.1) using BSSeeker2 [77]. Only the cytosines with coverage of at least five reads detected in all three cows were used for differential methylation analysis, which was performed with the R package, methylKit v1.8.1 [78]. Logistic regression model was used to separate the effect of individual variation and other covariates from the treatment effect. Since the control and treatment were paired samples, the full model $(\sim$ treatment + cow $)$ was used to control for the individual cow effect from the treatment effect. The genome was tiled for $100 \mathrm{bp}$ in order to find differentially methylated regions (DMRs). DMRs with at least two CpG sites with a methylation difference $\geq 10 \%$ and $q$-value $<0.05$ between sample groups were considered for further analysis. Ensembl gene annotation version 84 was used in the methylation analysis of genic regions, whereas $\mathrm{CpG}$ islands and repetitive element annotations for bosTau8 genome were obtained from the UCSC genome browser database (https://genome.ucsc.edu/).

Gene ontology over-representation and pathway analyses Gene ontology (GO) overrepresentation analysis of DMR-associated genes was performed using DAVID functional annotation tool [33, 34]. All annotated genes in Bos taurus genome were used as background for GO analysis. Pathway enrichment analysis was performed using the KEGG database available within DAVID platform, and with WikiPathways database (https://www. wikipathways.org/).

\section{Supplementary information}

Supplementary information accompanies this paper at https://doi.org/10 1186/s12864-020-06777-7.

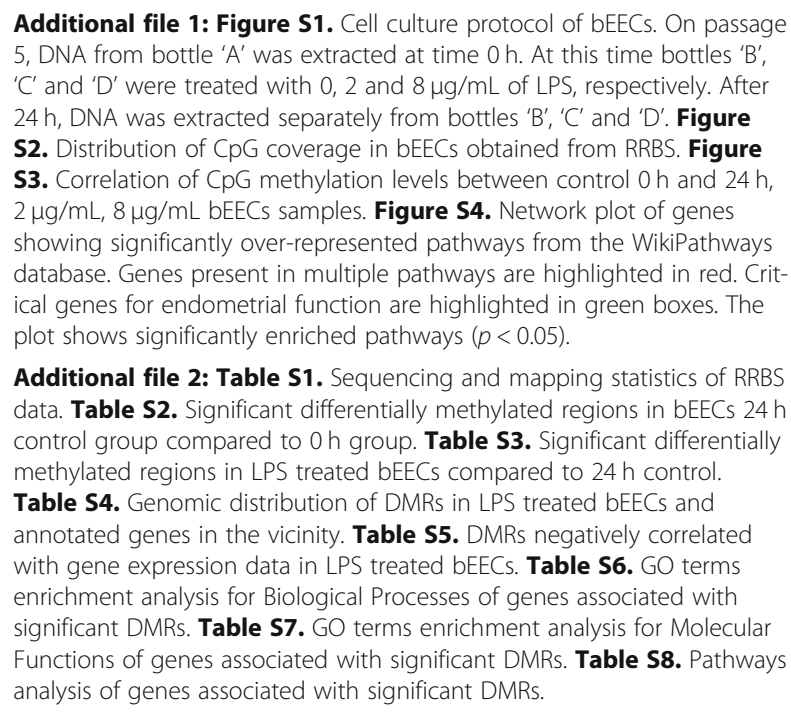

Additional file 2: Table S1. Sequencing and mapping statistics of RRBS data. Table S2. Significant differentially methylated regions in bEECs $24 \mathrm{~h}$ control group compared to $0 \mathrm{~h}$ group. Table S3. Significant differentially methylated regions in LPS treated bEECs compared to $24 \mathrm{~h}$ control. Table S4. Genomic distribution of DMRs in LPS treated bEECs and annotated genes in the vicinity. Table S5. DMRs negatively correlated with gene expression data in LPS treated bEECs. Table S6. GO terms enrichment analysis for Biological Processes of genes associated with significant DMRs. Table S7. GO terms enrichment analysis for Molecular Functions of genes associated with significant DMRs. Table S8. Pathways analysis of genes associated with significant DMRs.

\section{Abbreviations}

RRBS: Reduced Representation Bisulfite Sequencing; LPS: Lipopolysaccharide; bEECs: bovine endometrial epithelial cells; DMRs: Differentially Methylated Regions; E. coli: Escherichia coli; bosTau8: Bos taurus 8; GO: Gene ontology; KEGG: Kyoto Encyclopedia of Genes and Genomes; RNAseq: RNA sequencing; mRNA: messenger RNA; ENA: European Nucleotide Archive

\section{Acknowledgements}

We thank The Babraham Institute, UK, particularly Kristina Tabbada, for providing their platform for sample preparation and generating sequencing data. We thank SLU Bioinformatics Infrastructure (SLUBI) for management and processing of the sequencing data. Support by NBIS (National Bioinformatics Infrastructure Sweden) is gratefully acknowledged. 


\section{Authors' contributions}

P.H. and G.A. designed this research. N.J. and A.N. performed the bioinformatics and statistical analyses, interpreted the results and prepared the manuscript with Y. G, P.H. and G.A. Y.G. and M.C. isolated and prepared the bovine endometrial epithelial cells. Y.G. and E.I. and G. K performed the RRBS experiments and interpreted the results. P.H., M.C. and Y.G. coordinated sample collection, analyzed and interpreted clinical data. A.N., P.H., G.K., E.B-R. and G.A. advised on the analytic strategy and interpreted the results. All authors have read and approved the manuscript.

\section{Funding}

This work was performed with the financial support from the EU project "PROLIFIC" (Grant KBBE 311776-PR) covering partly the salary of Y.G. and a grant from Rajamangala University of Technology Srivijaya (RMUTSV) Thailand, covering most of running expenses for collection and preparation of biological material used and the scholarship of the PhD student Metasu Chanrot. Networking and short-term mission of Y.G. in Babraham institute was supported by the EU COST Action FA1201 (EPICONCEPT). The funding bodies did not participate in the design of the study and collection, analysis, and interpretation of data and in writing the manuscript. Open access funding provided by Swedish University of Agricultural Sciences.

\section{Availability of data and materials}

All RRBS raw sequencing data were deposited in the European Nucleotide Archive (ENA) under accession number PRJEB36023. Raw RNAseq sequencing data are also available in the ENA database under accession PRJEB34011. All reference data including reference genome sequence (Accession ID: GCA_000003055.4), CpG islands and repetitive element annotations for bosTau8 are available in the UCSC genome browser database (https:/genome.ucsc.edu/ ). Gene annotations (Accession ID: GCA_000003055.3) are available at Ensembl genome database https://www.ensembl.org/.

\section{Ethics approval and consent to participate}

Ethical approval was not required since the samples were collected from slaughter house.

\section{Consent for publication}

Not Applicable.

\section{Competing interests}

The authors have declared that no competing interests exist.

\section{Author details}

'Department of Animal Breeding and Genetics, Section of Molecular Genetics, Swedish University of Agricultural Sciences, Uppsala 750 07, Sweden. ${ }^{2}$ SLU-Global Bioinformatics Centre, Swedish University of Agricultural Sciences, Uppsala 750 07, Sweden. ${ }^{3}$ Department of Information Technology, University of the Punjab, Gujranwala Campus, Gujranwala, Pakistan. ${ }^{4}$ Department of Clinical Sciences, Division of Reproduction, Swedish University of Agricultural Sciences, Uppsala 750 07, Sweden. ${ }^{5}$ Faculty of Veterinary Science, Rajamangala University of Technology Srivijaya, Nakhon Si Thammarat 802 40, Thailand. 'Epigenetics Programme, The Babraham Institute, Cambridge, UK. ${ }^{7}$ Centre for Trophoblast Research, University of Cambridge, Cambridge, UK. ${ }^{8}$ Centre for Reproductive Biology in Uppsala, CRU, P.O. Box 7054, 75007 Uppsala, Sweden.

\section{Received: 19 January 2020 Accepted: 10 May 2020}

\section{Published online: 03 June 2020}

\section{References}

1. Lincke A, Drillich M, Heuwieser W. Subclinical endometritis in dairy cattle and its effect on fertility--a review of recent publications. Berl Munch Tierarztl Wochenschr. 2007;120(5-6):245-50.

2. Sheldon IM, Cronin J, Goetze L, Donofrio G, Schuberth HJ. Defining postpartum uterine disease and the mechanisms of infection and immunity in the female reproductive tract in cattle. Biol Reprod. 2009;81(6):1025-32.

3. Gilbert RO. The effects of endometritis on the establishment of pregnancy in cattle. Reprod Fertil Dev. 2011;24(1):252-7.

4. Graham MR, Bowdridge EC, Bowdridge SA, Holásková I, Elsasser TH, Dailey RA. Effect of lipopolysaccharide-induced immune responses on pregnancy loss in ewes. Open J Anim Sci. 2018;08(04):421-31.
5. Cronin JG, Turner ML, Goetze L, Bryant CE, Sheldon IM. Toll-like receptor 4 and MYD88-dependent signaling mechanisms of the innate immune system are essential for the response to lipopolysaccharide by epithelial and stromal cells of the bovine endometrium. Biol Reprod. 2012;86(2):51

6. Herath S, Fischer DP, Werling D, Williams EJ, Lilly ST, Dobson H, Bryant CE, Sheldon IM. Expression and function of toll-like receptor 4 in the endometrial cells of the uterus. Endocrinology. 2006;147(1):562-70.

7. Cronin JG, Kanamarlapudi V, Thornton CA, Sheldon IM. Signal transducer and activator of transcription-3 licenses toll-like receptor 4-dependent interleukin (IL)-6 and IL-8 production via IL-6 receptor-positive feedback in endometrial cells. Mucosal Immunol. 2016;9(5):1125-36.

8. Sheldon IM, Roberts MH. Toll-like receptor 4 mediates the response of epithelial and stromal cells to lipopolysaccharide in the endometrium. PLoS One. 2010;5(9):e12906.

9. Robertson SA, Moldenhauer LM. Immunological determinants of implantation success. Int J Dev Biol. 2014;58(2-4):205-17.

10. Guo Y, Chankeaw W, Chanrot M, Valarcher J, Chantarapratep P, Bage R, Bongcam-Rudloff E, Andersson G, Charpigny G, Humblot P. Changes induced by pathogens and metabolic stress on endometrial function in cattle: possible impacts of increased inflammation on fertility. Rev Bras Reprod Anim. 2019;43(n2):295-307.

11. Walker CG, Littlejohn MD, Meier S, Roche JR, Mitchell MD. DNA methylation is correlated with gene expression during early pregnancy in Bos taurus. Physiol Genomics. 2013;45(7):276-86.

12. Furst RW, Meyer HH, Schweizer G, Ulbrich SE. Is DNA methylation an epigenetic contribution to transcriptional regulation of the bovine endometrium during the estrous cycle and early pregnancy? Mol Cell Endocrinol. 2012;348(1):67-77.

13. Logan PC, Ponnampalam AP, Rahnama F, Lobie PE, Mitchell MD. The effect of DNA methylation inhibitor 5-Aza-2'-deoxycytidine on human endometrial stromal cells. Hum Reprod. 2010;25(11):2859-69.

14. Jha RK, Titus S, Saxena D, Kumar PG, Laloraya M. Profiling of E-cadherin, beta-catenin and $\mathrm{Ca}(2+)$ in embryo-uterine interactions at implantation. FEBS Lett. 2006;580(24):5653-60.

15. Li Q, Wang J, Armant DR, Bagchi MK, Bagchi IC. Calcitonin down-regulates E-cadherin expression in rodent uterine epithelium during implantation. J Biol Chem. 2002;277(48):46447-55.

16. Liu G, Zhang X, Lin H, Wang H, Li Q, Ni J, Zhu C. Effects of E-cadherin on mouse embryo implantation and expression of matrix metalloproteinase-2 and -9. Biochem Biophys Res Commun. 2006;343(3):832-8.

17. Matsuzaki S, Darcha C, Maleysson E, Canis M, Mage G. Impaired downregulation of E-cadherin and beta-catenin protein expression in endometrial epithelial cells in the mid-secretory endometrium of infertile patients with endometriosis. J Clin Endocrinol Metab. 2010;95(7):3437-45.

18. Rahnama F, Thompson B, Steiner M, Shafiei F, Lobie PE, Mitchell MD. Epigenetic regulation of E-cadherin controls endometrial receptivity. Endocrinology. 2009;150(3):1466-72.

19. Wu Y, Halverson G, Basir Z, Strawn E, Yan P, Guo SW. Aberrant methylation at HOXA10 may be responsible for its aberrant expression in the endometrium of patients with endometriosis. Am J Obstet Gynecol. 2005;193(2):371-80.

20. Novakovic B, Habibi E, Wang SY, Arts RJW, Davar R, Megchelenbrink W, Kim B, Kuznetsova T, Kox M, Zwaag J, et al. beta-Glucan reverses the epigenetic state of LPS-induced immunological tolerance. Cell. 2016;167(5):1354-68 e1314.

21. Sheldon IM, Price SB, Cronin J, Gilbert RO, Gadsby JE. Mechanisms of infertility associated with clinical and subclinical endometritis in high producing dairy cattle. Reprod Domest Anim. 2009;44(Suppl 3):1-9.

22. Singh J, Murray RD, Mshelia G, Woldehiwet Z. The immune status of the bovine uterus during the peripartum period. Vet J. 2008;175(3):301-9.

23. LeBlanc SJ. Interactions of metabolism, inflammation, and reproductive tract health in the postpartum period in dairy cattle. Reprod Domest Anim. 2012; 47(Suppl 5):18-30.

24. Walker CG, Littlejohn MD, Mitchell MD, Roche JR, Meier S. Endometrial gene expression during early pregnancy differs between fertile and subfertile dairy cow strains. Physiol Genomics. 2012;44(1):47-58.

25. Walker CG, Meier S, Hussein H, McDougall S, Burke CR, Roche JR, Mitchell MD. Modulation of the immune system during postpartum uterine inflammation. Physiol Genomics. 2015;47(4):89-101. 
26. Walker CG, Meier S, Littlejohn MD, Lehnert K, Roche JR, Mitchell MD. Modulation of the maternal immune system by the pre-implantation embryo. BMC Genomics. 2010;11:474.

27. Wang J, Yan X, Nesengani LT, Ding H, Yang L, Lu W. LPS-induces IL-6 and IL-8 gene expression in bovine endometrial cells "through DNA methylation". Gene. 2018:677:266-72.

28. Guo Y, van Schaik T, Jhamat N, Niazi A, Chanrot M, Charpigny G, Valarcher JF, Bongcam-Rudloff E, Andersson G, Humblot P. Differential gene expression in bovine endometrial epithelial cells after challenge with LPS; specific implications for genes involved in embryo maternal interactions. PLoS One. 2019;14(9):e0222081.

29. Dohmen MJ, Joop K, Sturk A, Bols PE, Lohuis JA. Relationship between intrauterine bacterial contamination, endotoxin levels and the development of endometritis in postpartum cows with dystocia or retained placenta. Theriogenology. 2000;54(7):1019-32

30. Williams EJ, Fischer DP, Noakes DE, England GC, Rycroft A, Dobson H, Sheldon IM. The relationship between uterine pathogen growth density and ovarian function in the postpartum dairy cow. Theriogenology. 2007; 68(4):549-59.

31. Chanrot M, Guo Y, Dalin AM, Persson E, Bage R, Svensson A, Gustafsson H, Humblot P. Dose related effects of LPS on endometrial epithelial cell populations from dioestrus cows. Anim Reprod Sci. 2017;177:12-24.

32. Piras C, Guo Y, Soggiu A, Chanrot M, Greco V, Urbani A, Charpigny G, Bonizzi L, Roncada P, Humblot P. Changes in protein expression profiles in bovine endometrial epithelial cells exposed to E. coli LPS challenge. Mol BioSyst. 2017;13(2):392-405

33. Huang da W, Sherman BT, Lempicki RA. Systematic and integrative analysis of large gene lists using DAVID bioinformatics resources. Nat Protoc. 2009; 4(1):44-57.

34. Huang da W, Sherman BT, Lempicki RA. Bioinformatics enrichment tools: paths toward the comprehensive functional analysis of large gene lists. Nucleic Acids Res. 2009;37(1):1-13.

35. Houshdaran S, Zelenko Z, Irwin JC, Giudice LC. Human endometrial DNA methylome is cycle-dependent and is associated with gene expression regulation. Mol Endocrinol. 2014;28(7):1118-35.

36. Saare M, Modhukur V, Suhorutshenko M, Rajashekar B, Rekker K, Soritsa D, Karro H, Soplepmann P, Soritsa A, Lindgren CM, et al. The influence of menstrual cycle and endometriosis on endometrial methylome. Clin Epigenetics. 2016;8:2

37. Mortlock S, Restuadi R, Levien R, Girling JE, Holdsworth-Carson SJ, Healey M, Zhu Z, Qi T, Wu Y, Lukowski SW, et al. Genetic regulation of methylation in human endometrium and blood and gene targets for reproductive diseases. Clin Epigenetics. 2019;11(1):49.

38. Chen J, Wu Y, Sun Y, Dong X, Wang Z, Zhang Z, Xiao Y, Dong G. Bacterial Lipopolysaccharide Induced Alterations of Genome-Wide DNA Methylation and Promoter Methylation of Lactation-Related Genes in Bovine Mammary Epithelial Cells. Toxins (Basel). 2019;11(5). https://doi.org/10.3390/ toxins 11050298

39. Korkmaz FT, Kerr DE. Genome-wide methylation analysis reveals differentially methylated loci that are associated with an age-dependent increase in bovine fibroblast response to LPS. BMC Genomics. 2017;18(1):405.

40. Engdahl E, Dunn N, Niehusmann P, Wideman S, Wipfler P, Becker AJ, Ekstrom TJ, Almgren M, Fogdell-Hahn A. Human Herpesvirus 6B Induces Hypomethylation on Chromosome 17p13.3, Correlating with Increased Gene Expression and Virus Integration. J Virol. 2017;91(11). https://doi.org/ 10.1128/JVI.02105-16

41. Macnab JC, Adams RL, Rinaldi A, Orr A, Clark L. Hypomethylation of host cell DNA synthesized after infection or transformation of cells by herpes simplex virus. Mol Cell Biol. 1988;8(4):1443-8.

42. Pacis A, Tailleux L, Morin AM, Lambourne J, Maclsaac JL, Yotova V, Dumaine A, Danckaert A, Luca F, Grenier JC, et al. Bacterial infection remodels the DNA methylation landscape of human dendritic cells. Genome Res. 2015; 25(12):1801-11.

43. Blasco MA. The epigenetic regulation of mammalian telomeres. Nat Rev Genet. 2007:8(4):299-309.

44. Gadalla SM, Katki HA, Shebl FM, Giri N, Alter BP, Savage SA. The relationship between DNA methylation and telomere length in dyskeratosis congenita. Aging Cell. 2012;11(1):24-8.

45. Maekawa R, Yagi S, Ohgane J, Yamagata Y, Asada H, Tamura I, Sugino N, Shiota K. Disease-dependent differently methylated regions (D-DMRs) of
DNA are enriched on the $X$ chromosome in uterine leiomyoma. J Reprod Dev. 2011;57(5):604-12.

46. Kawakami T, Zhang C, Taniguchi T, Kim CJ, Okada Y, Sugihara H, Hattori T, Reeve AE, Ogawa O, Okamoto K. Characterization of loss-of-inactive $X$ in Klinefelter syndrome and female-derived cancer cells. Oncogene. 2004; 23(36):6163-9.

47. Sirchia SM, Ramoscelli L, Grati FR, Barbera F, Coradini D, Rossella F, Porta G, Lesma $E$, Ruggeri A, Radice $P$, et al. Loss of the inactive $X$ chromosome and replication of the active $\mathrm{X}$ in BRCA1-defective and wild-type breast cancer cells. Cancer Res. 2005;65(6):2139-46.

48. Li L, Yang XJ. Molecular and functional characterization of histone Deacetylase 4 (HDAC4). Methods Mol Biol. 2016;1436:31-45.

49. Kaowinn S, Jun SW, Kim CS, Shin DM, Hwang YH, Kim K, Shin B, Kaewpiboon C, Jeong $\mathrm{HH}$, Koh SS, et al. Increased EGFR expression induced by a novel oncogene, CUG2, confers resistance to doxorubicin through Stat1-HDAC4 signaling. Cell Oncol (Dordr). 2017;40(6):549-61.

50. Sun Y, Qin B. Long noncoding RNA MALAT1 regulates HDAC4-mediated proliferation and apoptosis via decoying of miR-140-5p in osteosarcoma cells. Cancer Med. 2018;7(9):4584-97.

51. Cai JY, Xu TT, Wang Y, Chang JJ, Li J, Chen XY, Chen X, Yin YF, Ni XJ. Histone deacetylase HDAC4 promotes the proliferation and invasion of glioma cells. Int J Oncol. 2018;53(6):2758-68.

52. Marroncelli N, Bianchi M, Bertin M, Consalvi S, Saccone V, De Bardi M, Puri PL, Palacios D, Adamo S, Moresi V. HDAC4 regulates satellite cell proliferation and differentiation by targeting P21 and Sharp1 genes. Sci Rep. 2018;8(1):3448.

53. Fan X, Krieg S, Hwang JY, Dhal S, Kuo CJ, Lasley BL, Brenner RM, Nayak NR. Dynamic regulation of Wnt7a expression in the primate endometrium: implications for postmenstrual regeneration and secretory transformation. Endocrinology. 2012;153(3):1063-9.

54. Liu Y, Meng F, Xu Y, Yang S, Xiao M, Chen X, Lou G. Overexpression of Wnt7a is associated with tumor progression and unfavorable prognosis in endometrial cancer. Int J Gynecol Cancer. 2013;23(2):304-11.

55. Ingaramo PI, Milesi MM, Schimpf MG, Ramos JG, Vigezzi L, Munoz-de-Toro M, Luque EH, Varayoud J. Endosulfan affects uterine development and functional differentiation by disrupting Wnt7a and beta-catenin expression in rats. Mol Cell Endocrinol. 2016;425:37-47.

56. Pazhohan A, Amidi F, Akbari-Asbagh F, Seyedrezazadeh E, Farzadi L, Khodarahmin M, Mehdinejadiani S, Sobhani A. The Wnt/beta-catenin signaling in endometriosis, the expression of total and active forms of betacatenin, total and inactive forms of glycogen synthase kinase-3beta, WNT7a and DICKKOPF-1. Eur J Obstet Gynecol Reprod Biol. 2018;220:1-5.

57. Dunlap KA, Filant J, Hayashi K, Rucker EB 3rd, Song G, Deng JM, Behringer RR, DeMayo FJ, Lydon J, Jeong JW, et al. Postnatal deletion of Wnt7a inhibits uterine gland morphogenesis and compromises adult fertility in mice. Biol Reprod. 2011;85(2):386-96.

58. Piotrowska-Tomala KK, Siemieniuch MJ, Szostek AZ, Korzekwa AJ, WoclawekPotocka I, Galvao AM, Okuda K, Skarzynski DJ. Lipopolysaccharides, cytokines, and nitric oxide affect secretion of prostaglandins and leukotrienes by bovine mammary gland epithelial cells. Domest Anim Endocrinol. 2012:43(4):278-88.

59. Mishra B, Koshi K, Kizaki K, Ushizawa K, Takahashi T, Hosoe M, Sato T, Ito A Hashizume K. Expression of ADAMTS1 mRNA in bovine endometrium and placenta during gestation. Domest Anim Endocrinol. 2013;45(1):43-8.

60. Keightley MC, Sales KJ, Jabbour HN. PGF2alpha-F-prostanoid receptor signalling via ADAMTS1 modulates epithelial cell invasion and endothelial cell function in endometrial cancer. BMC Cancer. 2010;10:488.

61. Esselens C, Malapeira J, Colome N, Casal C, Rodriguez-Manzaneque JC, Canals F, Arribas J. The cleavage of semaphorin 3C induced by ADAMTS1 promotes cell migration. J Biol Chem. 2010;285(4):2463-73.

62. Rodriguez-Manzaneque JC, Carpizo D, Plaza-Calonge Mdel C, Torres-Collado AX, Thai SN, Simons M, Horowitz A, Iruela-Arispe ML. Cleavage of syndecan4 by ADAMTS1 provokes defects in adhesion. Int J Biochem Cell Biol. 2009; 41(4):800-10.

63. Bamberger AM, Minas V, Kalantaridou SN, Radde J, Sadeghian H, Loning T, Charalampopoulos I, Brummer J, Wagener C, Bamberger CM, et al. Corticotropin-releasing hormone modulates human trophoblast invasion through carcinoembryonic antigen-related cell adhesion molecule-1 regulation. Am J Pathol. 2006;168(1):141-50.

64. Krendl C, Shaposhnikov D, Rishko V, Ori C, Ziegenhain C, Sass S, Simon L, Muller NS, Straub T, Brooks KE, et al. GATA2/3-TFAP2A/C transcription factor 
network couples human pluripotent stem cell differentiation to trophectoderm with repression of pluripotency. Proc Natl Acad Sci U S A. 2017;114(45):E9579-88.

65. Wang X, Peng S, Cui K, Hou F, Ding J, Li A, Wang M, Geng L. MicroRNA-576$5 p$ enhances the invasion ability of trophoblast cells in preeclampsia by targeting TFAP2A. Mol Genet Genomic Med. 2019;8:e1025.

66. Corti F, Finetti F, Ziche M, Simons M. The syndecan-4/protein kinase Calpha pathway mediates prostaglandin E2-induced extracellular regulated kinase (ERK) activation in endothelial cells and angiogenesis in vivo. J Biol Chem. 2013;288(18):12712-21.

67. Xu H, Czerwinski P, Hortmann M, Sohn HY, Forstermann U, Li H. Protein kinase $\mathrm{C}$ alpha promotes angiogenic activity of human endothelial cells via induction of vascular endothelial growth factor. Cardiovasc Res. 2008;78(2): 349-55.

68. Zhang Q, Wang D, Singh NK, Kundumani-Sridharan V, Gadiparthi L, Rao Ch M, Rao GN. Activation of cytosolic phospholipase A2 downstream of the Src-phospholipase D1 (PLD1)-protein kinase C gamma (PKCgamma) signaling axis is required for hypoxia-induced pathological retinal angiogenesis. J Biol Chem. 2011;286(25):22489-98.

69. Lu Y, Li Z, Xie B, Song Y, Ye X, Liu P. hsa-miR-20a-5p attenuates allergic inflammation in HMC-1 cells by targeting HDAC4. Mol Immunol. 2019;107: 84-90.

70. Moon J, Kaowinn S, Cho IR, Min DS, Myung H, Oh S, Kaewpiboon C, Kraemer $\mathrm{OH}$, Chung YH. Hepatitis $\mathrm{C}$ virus core protein enhances hepatocellular carcinoma cells to be susceptible to oncolytic vesicular stomatitis virus through down-regulation of HDAC4. Biochem Biophys Res Commun. 2016;474(3):428-34.

71. Yang D, Xiao C, Long F, Su Z, Jia W, Qin M, Huang M, Wu W, Suguro R, Liu $X$, et al. HDAC4 regulates vascular inflammation via activation of autophagy. Cardiovasc Res. 2018;114(7):1016-28.

72. Zenke K, Muroi M, Tanamoto Kl. AKT1 distinctively suppresses MyD88depenedent and TRIF-dependent toll-like receptor signaling in a kinase activity-independent manner. Cell Signal. 2018;43:32-9.

73. Singer JW, Fleischman A, Al-Fayoumi S, Mascarenhas JO, Yu Q, Agarwal A. Inhibition of interleukin-1 receptor-associated kinase 1 (IRAK1) as a therapeutic strategy. Oncotarget. 2018;9(70):33416-39.

74. Socha BM, Lada P, Szczepanska AA, Lupicka M, Korzekwa AJ. The influence of experimentally induced endometritis on the PPAR expression profile in the bovine endometrium. Theriogenology. 2018;122:74-83.

75. Chankeaw W, Guo YZ, Bage R, Svensson A, Andersson G, Humblot P. Elevated non-esterified fatty acids impair survival and promote lipid accumulation and pro-inflammatory cytokine production in bovine endometrial epithelial cells. Reprod Fertil Dev. 2018;30:1770-8.

76. Babraham Bioinformatics Trim Galore. https:/www.bioinformatics.babraham. ac.uk/projects/trim_galore/..

77. Guo W, Fiziev P, Yan W, Cokus S, Sun X, Zhang MQ, Chen PY, Pellegrini M. BS-Seeker2: a versatile aligning pipeline for bisulfite sequencing data. BMC Genomics. 2013;14:774.

78. Akalin A, Kormaksson M, Li S, Garrett-Bakelman FE, Figueroa ME, Melnick A, Mason CE. methylKit: a comprehensive R package for the analysis of genome-wide DNA methylation profiles. Genome Biol. 2012;13(10):R87.

\section{Publisher's Note}

Springer Nature remains neutral with regard to jurisdictional claims in published maps and institutional affiliations.

Ready to submit your research? Choose BMC and benefit from:

- fast, convenient online submission

- thorough peer review by experienced researchers in your field

- rapid publication on acceptance

- support for research data, including large and complex data types

- gold Open Access which fosters wider collaboration and increased citations

- maximum visibility for your research: over $100 \mathrm{M}$ website views per year

At BMC, research is always in progress.

Learn more biomedcentral.com/submissions 